\title{
Description of the song of the Nilgiri Thrush (Zoothera [aurea] neilgherriensis) and song differentiation across the Zoothera dauma species complex
}

\author{
Jason T. Weir ${ }^{1,2,3^{*}}$ (1)
}

\begin{abstract}
Background: Taxonomic treatment of the Zoothera dauma species complex is highly variable and has been hampered by the absence of song recordings for the Nilgiri Thrush (Zoothera [aurea] neilgherriensis).

Methods: I obtained two recordings of the song of neigherriensis from southern Indian. Here I publish sonograms and analyze song recordings for all but one currently described taxon from the Eurasian portion of the geographic range of this species complex. Principal component analyses were used to investigate song differences between taxa.

Results: The song of neigherriensis is a highly complex series of strophes remarkably similar to the song of the insular Zoothera major. Vocal analyses across the complex indicate four key groups of taxa differentiated in their songs: (1) simple flat whistled songs which include the northern aurea, toratugumi and the undescribed Taiwan population; (2) eastern populations of dauma (reported here for the first time) which sing like northern birds but with much broader bandwidth, (3) strongly down-slurred, thin whistles of tropical resident imbricata of Sri Lanka and horsfieldi of Indonesia, and (4) highly complex songs of Himalayan dauma, neilgherriensis and major.

Conclusions: Zoothera dauma is unlikely to represent a single species given the simple singing populations from its eastern range and highly complex song from the Himalayan portion of its range. neilgherriensis should either be transferred from Zoothera aurea, where it is currently classified as a subspecies, and be placed as a subspecies within $Z$. dauma from the Himalayas or it should be recognized as a distinct species. Given the small number of songs available for analyses, I suggest the former course until it can be clearly demonstrated that neilgherriensis and Himalayan dauma are vocally distinct.
\end{abstract}

Keywords: Nilgiri Thrush, neilgherriensis, Zoothera dauma, Song, Taxonomy

\section{Background}

The Zoothera dauma species complex contains eight taxa (dauma, aurea, toratugumi, iriomotensis, major, horsfieldi, neilgherriensis, imbricata) on the Eurasian side of Wallace's Line (Fig. 1), with additional taxa distributed in Australasia which will not be considered here. The Eurasian taxa are often considered to comprise a single, highly

\footnotetext{
*Correspondence: jason.weir@utoronto.ca

${ }^{1}$ Department of Ecology and Evolutionary Biology, University of Toronto, Toronto, ON M1C 1A4, Canada

Full list of author information is available at the end of the article
}

polytypic species, with taxa differing in body dimensions and/or plumage and some of them also in song (del Hoyo et al. 2005). Alternatively, these differences have led to recognition of as many as six species $(Z$. dauma, $Z$. aurea which also includes toratugumi and iriomotensis, $Z$. major, Z. horsfieldi, Z. neilgherriensis, and Z. imbricata) (Sangster et al. 1998; Rasmussen and Anderton 2005), though del Hoyo and Collar (2016) recently recognized only three species: (1) $Z$. dauma with a highly variable song, (2) $Z$. major with a song like $Z$. dauma but with larger body size, and (3) Z. aurea which combines all the 


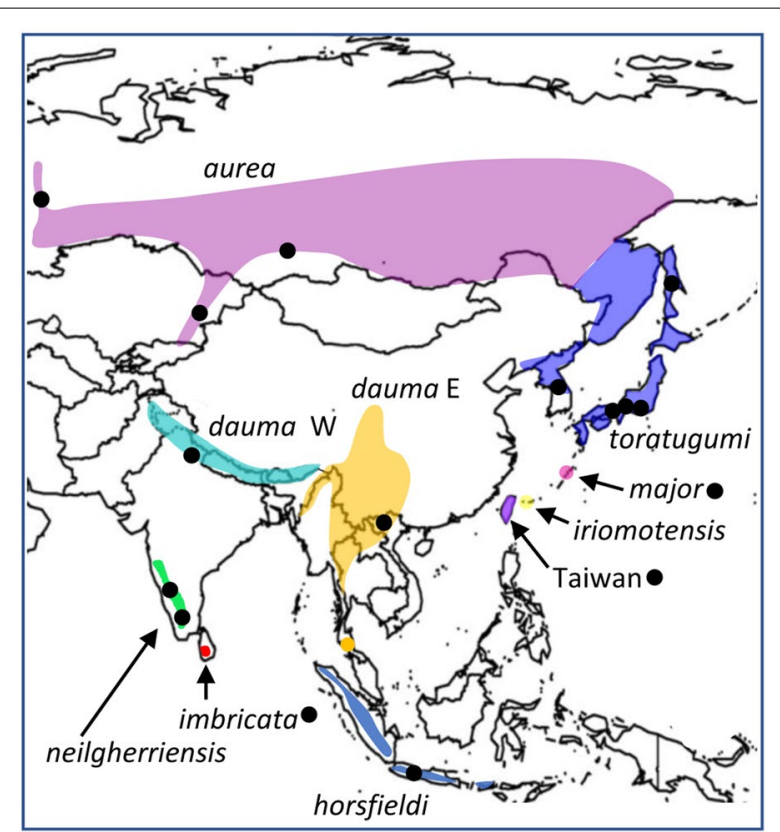

Fig. 1 Geographic range of the eight taxa which make up the Z. dauma species complex with the subspecies identity of the Taiwan population uncertain. The precise border between aurea and toratugumi is uncertain. The range of dauma is shown as two populations: dauma $\mathrm{W}$ represents western populations from the Himalayas where the type specimen of dauma was derived; dauma E from approximately Sichuan and Yunnan eastwards was previously considered a distinct taxon socia (Thayer and Bangs 1912), though the name affinis has also been applied to populations (possibly overwintering migrants) from southern Thailand (Richmond 1902). The exact division between these two populations requires further study. The population on Taiwan island has variously been placed in affinis, horsfieldi, or toratugumi/aurea or have been recognized as an endemic taxon hancii. Black dots represent sampling locations for song vocalizations utilized in this study

other Eurasian taxa on the pretense that they shared a similar simple song consisting of a flat whistle.

The song of the Nilgiri Thrush (neilgherriensis) - geographically isolated in the Western Ghats of India-has never been described, leading Clement and Hathway (2000) to conclude that if "neilgherriensis does in fact sing, it may be of such quality and/or given for so short a period that it has remained undetected." del Hoyo and Collar (2016) assigned neilgherriensis to $Z$. aurea, given its geographic proximity to Z. a. imbricata of Sri Lanka, which, like other taxa assigned to $Z$. aurea, has a simple song comprised of long whistled notes. Alternatively, neilgherriensis could be allied with $Z$. dauma distributed to the north.

Like neilgherriensis, recordings of many forms of the $Z$. dauma complex are scare. For example, despite its broad geographic range, only a single recording of dauma was available in the Maculauy Library and none were found on Xeno-Canto. Likewise, while the song of horsfieldi was verbally described (Clement and Hathway 2000), only a single song was available from a private recording and no sonograms have previously been published or analyzed. The song of imbricata was first recorded in 1997 (Clement and Hathway 2000). In contrast, many recordings are available for the migratory forms aurea and toratugumi and for the insular form major. This dearth of recordings for many taxa has made assessment of species limits in this complex difficult.

Here I describe the song of neilgherriensis from recordings I made from two separate individuals at different localities in 2008. I obtained at least one recording for all Eurasian members of the $Z$. dauma complex, with the sole exception of the recently described insular subspecies Z. a. iriomotensis of Japan. I performed a principal component analysis of songs from across the species complex to determine if neilgherriensis is vocally distinctive, and whether it groups more closely with $Z$. aurea or $Z$. dauma. Using this dataset I discuss the biogeographic patterns of song differentiation in the $Z$. dauma complex and its taxonomic implications.

\section{Methods}

Digital recordings were obtained using a Sennheiser K6/ME-62 omnidirectional microphone mounted in a Mineroff Electronics SME-PR-1000 parabolic reflector and recorded in 16-bit wav format into an Edirol digital recorder. On March 16, 2008, I obtained a recording of the song of neilgherriensis at $1930 \mathrm{~m}$ from Pampadumchola National Park, Kerala, near Top Station (in the vicinity of $10.125^{\circ} \mathrm{N}, 77.252^{\circ} \mathrm{W}$ ) at around $7 \mathrm{AM}$ under clear conditions. The bird was not seen prior to or during the recording, but the individual briefly responded to playback of the recording immediately afterward. That evening, I edited the song in RAVEN Pro 1.5 (Cornell Laboratory of ornithology, Ithaca, USA) to shorten a long interval between two episodes of singing on the recording, and to minimize background noises. The next day I encountered a second individual of $Z$. neilgherriensis in a different section of the park (ca. $10.132^{\circ} \mathrm{N} ; 77.252^{\circ} \mathrm{W}$; $1860 \mathrm{~m}$ ) at $10 \mathrm{AM}$. The bird was not vocalizing. I placed a Pignose field speaker $12 \mathrm{~m}$ from the bird and played the edited recording. The bird approached to $9 \mathrm{~m}$ from the speaker and flew back and forth several times in the vicinity of the speaker without approaching any closer. The song of a second bird was recorded and the bird observed well and positively identified at close range at ca. $2200 \mathrm{~m}$ in Cairn Hill Reserve Forest near Ooty, Tamil Nadu on March 19, 2008 at 11:30 AM under light rain.

Songs of all other taxa except iriomotensis (song undescribed) were obtained from Xeno-canto (2017), the Macualay Library (2017), AvoCET (2017), and the 
private holdings of Craig Robson and Bas van Balen and were analyzed together with my neilgherriensis vocalizations in Raven Pro using the default settings. Eight transformed measurements were obtained for each song strophe (a single phrase usually consisting of one note, more rarely of two or more notes strung in quick succession, with strophes separated by a pause) in these recordings (see RAVEN Pro manual for precise definitions): (1) centre frequency, (2) 90 percentile bandwidth, (3) strophe length, (4) aggregate entropy, and (5) change in frequency. The latter was the difference in centre frequency of the first and last $0.1 \mathrm{~s}$ of the song strophe averaged across five or more song strophes and divided by the standard deviation across song strophes. This value is positive if strophes decline in frequency and negative if they increase. When possible, I analyzed 10 or more strophes per song. Mean values across strophes within a recording were obtained for the first four measurements and these were log transformed. A principal component analysis was performed in R 3.4.0 (R Core Team 2017) using the prcomp function with data centered and scaled.

\section{Results}

Table 1 compares strophe length and frequency between taxa and Fig. 2 shows examples of the range of song variation across and within taxa. The song of neilgherriensis (Table 1, Fig. 2) is comprised of a slow series of highly variable strophes that varied greatly in pitch. Harmonics were not observed on either sound recording. Notes were blurry rather than pure whistles and strophe shape varied greatly and included various fast warbles, as well as both strongly down-slurred and upslurred strophes, and a variety of strophes with more complex shape. Strophe length was similar for the two recordings and ranged from 0.1 to $0.8 \mathrm{~s}$ (Table 1). Spacing between notes differed between the two recordings with the Top Station recording at a much slower pace. (Top Station, range $=2.8-8.5 \mathrm{kHz}$; mean $=5.4 \mathrm{kHz}$, $n=13$; Ooty, range $=0.2-4.39 \mathrm{~s}$; mean $=2.2 \mathrm{~s}, n=36$ ).

The first PC was positively loaded mostly by bandwidth and aggregate entropy and negatively loaded by song length. I interpret large values to represent short strophes possessing high variability in frequency within each strophe. neilgherriensis, dauma (Himalayas) and major had large values for PC 1, while aurea, toratugumi, the Taiwan population, imbricata and horsfieldi had small values. The Vietnam recording of dauma had intermediate values. The second PC was negatively loaded by centre frequency and positively loaded by change in frequency. Large values indicate songs with low frequency in which frequency declined through the song. This PC clearly differentiated imbricata and horsfieldi from other species. Both these species show a strong downturn (i.e. negative slope) through their songs (Fig. 2). I also plotted change in frequency versus log bandwidth (Fig. 3c) as these two variables clearly separate out the various groups.

\section{Discussion}

Songs of the various taxa fall into four, mostly distinct groupings: (1) simple flat whistled songs sung by the migratory aurea, toratugumi, and the sedentary population from Taiwan island; (2) simple songs similar to group 1 , but with much broader bandwidth sung by dauma from Vietnam; (3) simple down-slurred whistled songs sung by imbricata and horsfieldi; and (4) complex songs with varied strophes sung by major, western Himalayan dauma, and neilgherriensis (Figs. 2, 3). These four vocal groupings are at odds with the taxonomic treatment in del Hoyo and Collar (2016) in two respects. First, del Hoyo and Collar (2016) treated neilgherriensis as a subspecies of $Z$. aurea. However, the complex strophes that

Table 1 Mean (range) for 5 measurements from songs of the Z. dauma species complex

\begin{tabular}{|c|c|c|c|c|c|c|}
\hline Taxon & $n$ & Length (s) & Bandwidth (s) & Centre frequency $(\mathrm{kHz})$ & Lower frequency (kHz) & Upper frequency $(\mathbf{k H z})$ \\
\hline neilgherriensis & 2 & $0.31(0.1-0.8)$ & $0.81(0.34-1.98)$ & $2.26(1.38-3.70)$ & $1.86(0.95-3.53)$ & $2.67(1.98-4.05)$ \\
\hline major & 10 & $0.34(0.04-0.9)$ & $1.38(0.38-6.80)$ & $2.85(1.50-8.72)$ & $2.26(1.13-8.53)$ & $3.65(1.81-10.59)$ \\
\hline dauma (Himalayas) & 1 & $0.15(0.1-0.3)$ & $1.72(0.52-5.34)$ & $4.06(1.46-7.06)$ & $3.27(1.29-6.20)$ & $4.99(2.15-8.53)$ \\
\hline dauma (Vietnam) & 1 & $0.46(0.4-0.5)$ & $0.52(0.26-0.60)$ & $2.67(2.15-3.62)$ & $2.42(2.07-3.53)$ & $2.93(2.50-3.79)$ \\
\hline aurea & 11 & $0.57(0.3-1.1)$ & $0.14(0.09-0.26)$ & $2.70(1.29-4.91)$ & $2.63(1.29-4.82)$ & $2.77(1.38-5.00)$ \\
\hline toratugumi & 9 & $0.45(0.3-0.7)$ & $0.17(0.09-0.34)$ & $2.64(1.81-5.86)$ & $2.56(1.72-5.68)$ & $2.73(1.89-6.03)$ \\
\hline Taiwan Is. & 2 & $0.57(0.3-0.8)$ & $0.16(0.09-0.26)$ & $2.75(1.55-5.25)$ & $2.67(1.46-5.17)$ & $2.84(1.64-5.34)$ \\
\hline imbricata & 2 & $0.40(0.3-0.6)$ & $0.29(0.17-0.43)$ & $2.03(1.98-2.15)$ & $1.91(1.81-1.98)$ & $2.20(2.15-2.41)$ \\
\hline horsfieldi & 1 & $0.49(0.4-0.6)$ & $0.49(0.34-0.52)$ & $2.70(2.58-2.76)$ & $2.57(2.50-2.67)$ & $3.02(2.93-3.10)$ \\
\hline
\end{tabular}

Frequency measurements and bandwidth are in units of kilohertz and length in seconds. Lower Frequency is measured at the 5th percentile of energy and Upper Frequency at the 95 th percentile. Bandwidth occurs between these. Song length is measured between the 5 th and 95 th percentile energies. Mean values for each measurement were obtained across strophes within a recording and then were averaged across recordings for each taxon to obtain mean values. The range represents low and high values obtained across replicate strophes both within and between individuals 


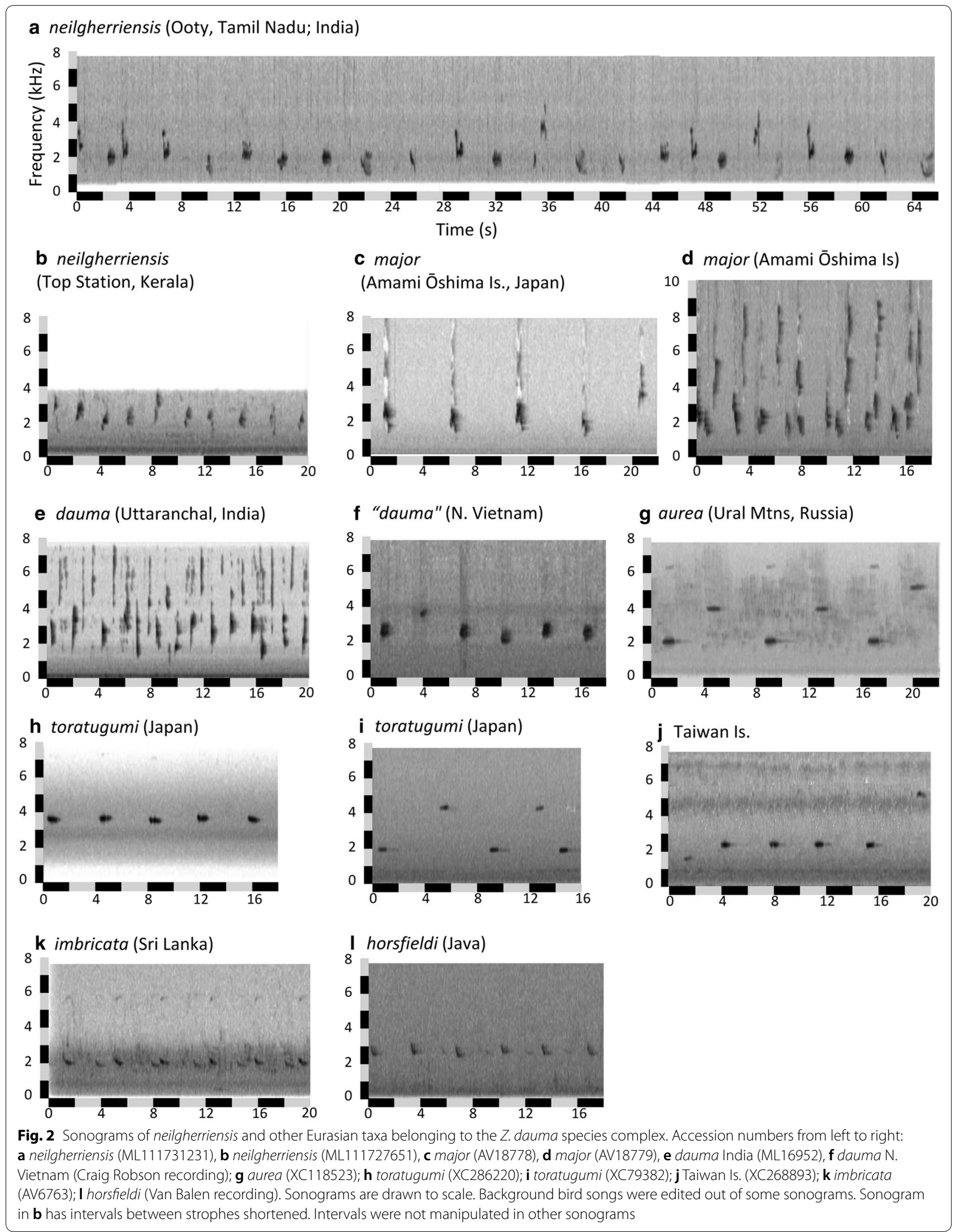


Table 2 Recordings analyzed

\begin{tabular}{|c|c|c|c|}
\hline Taxon & Country & Region & Accession number \\
\hline toratugumi & Japan & Kyoto & $\begin{array}{l}\text { XC305906, XC362118 } \\
\text { XC193561 }\end{array}$ \\
\hline toratugumi & Japan & Tokyo & XC372124, XC372117 \\
\hline toratugumi & Japan & Mt. Fuji & ML14145 \\
\hline toratugumi & South Korea & Daejeon & $\begin{array}{l}\text { XC128641, XC128642, } \\
\text { XC79669 }\end{array}$ \\
\hline toratugumi & Russia & Sahalinskaja & ML99837 \\
\hline aurea & Russia & Primorskiy & $\begin{array}{l}\text { XC268117, } \\
\text { ML91840:ML91844 }\end{array}$ \\
\hline aurea & Russia & Krasnoyarsk & XC377207 \\
\hline aurea & Russia & Perm & XC364885 \\
\hline aurea & Khazakistan & & XC150106, XC373092 \\
\hline$?$ & China & Taiwan & XC48162, XC278274 \\
\hline major & Japan & Amami-Oshima Is. & $\begin{array}{l}\text { AV18778, AV18779, } \\
\text { XC191079, } \\
\text { XC155984, } \\
\text { XC191083, } \\
\text { XC191080, } \\
\text { XC286175, } \\
\text { XC191087, } \\
\text { XC363833, } \\
\text { XC363831 }\end{array}$ \\
\hline dauma & India & Uttarakhand & ML169652 \\
\hline dauma & Vietnam & Tam Dao & $\begin{array}{l}\text { Craig Robson record- } \\
\text { ing }\end{array}$ \\
\hline neilgherriensis & India & Tamil Nadu (Ooty) & ML111731231 \\
\hline neilgherriensis & India & Kerala (Top Station) & ML111727651 \\
\hline imbricata & Sri Lanka & Horton Plains & $\begin{array}{l}\text { AV6763 ( } 2 \text { individuals } \\
\text { on recording) }\end{array}$ \\
\hline horsfieldi & Indonesia & Java & $\begin{array}{l}\text { Bas van Balen record- } \\
\text { ing }\end{array}$ \\
\hline
\end{tabular}

Libraries: $\mathrm{XC}=$ Xeno-cantos, $\mathrm{ML}=$ Macaulay Library, $\mathrm{AV}=\mathrm{AvoCET}$

comprise the song of neilgherriensis are starkly different from the simple down-slurred whistles of $Z$. a. imbricata or the mostly flat whistles of aurea and toratugumi, and instead are similar to the recording of $Z$. dauma from the western Himalayas and remarkably similar to certain individuals of Z. major (Table 2, Figs. 2, 3). Second, the songs from northern Vietnam comprised simple, flat whistles similar to those from aurea, toratugumi and the unassigned Taiwan population, and starkly different from the recording of $Z$. dauma from the western Himalayas. However, the Vietnam recording differed from all sampled individuals of aurea, toratugumi and the Taiwan population in possessing a much larger strophe bandwidth (intermediate in this respect between these taxa and major) and thus is unlikely to represent the song of an overwintering or migrant individual of these other taxa. While this larger strophe bandwidth results in the Vietnam recording appearing intermediate between the

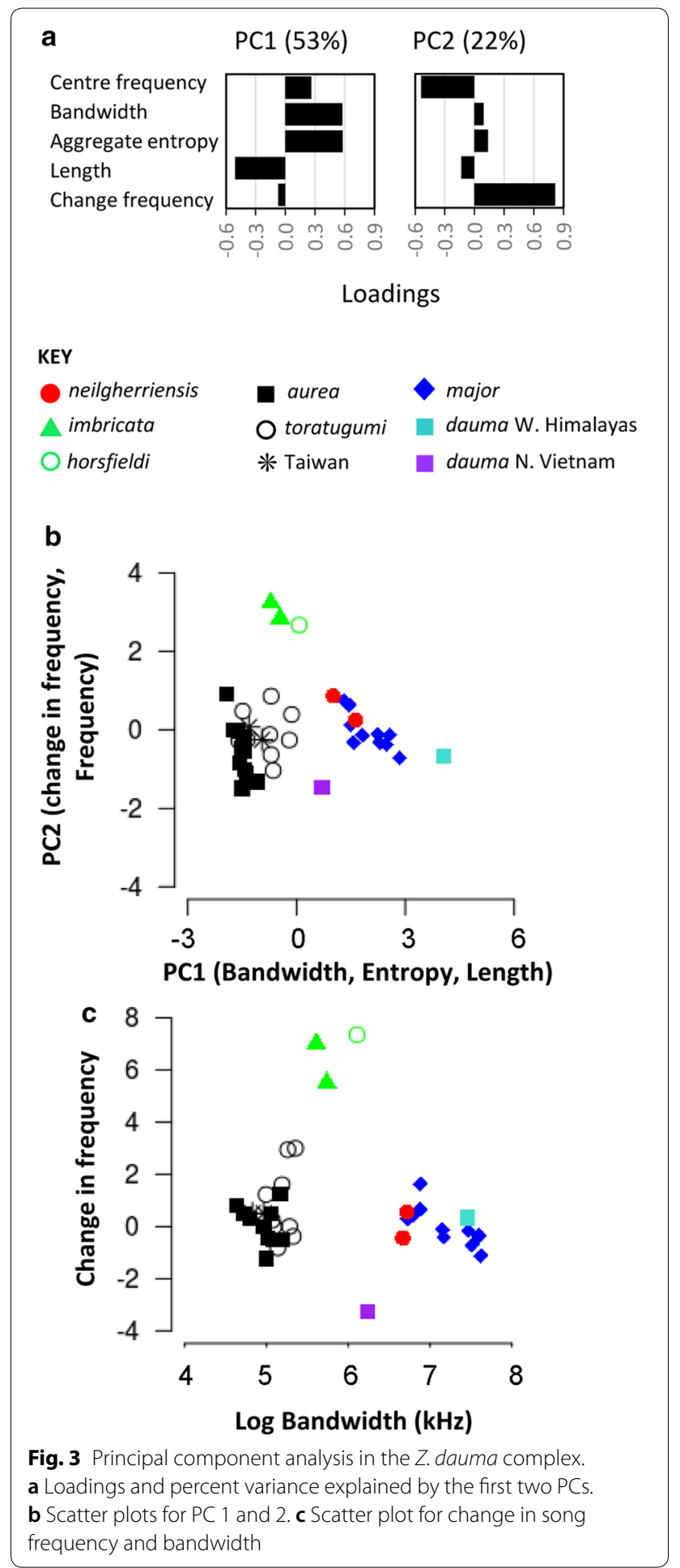

simple (generally narrow bandwidth) and complex (large bandwidth) groupings in PCA (Fig. 3), these recordings are otherwise consistent with the simple flat whistles produced by other members of the simple grouping 
(Fig. 2). These results suggest the presence of a distinct taxon allied with $Z$. aurea rather than $Z$. dauma in the eastern part of its range (e.g. birds of Yunnan, Sichuan and surrounding areas were previously described as $Z$. d. socia; Thayer and Bangs 1912). Alternatively, possible plumage intergradation between $Z$. aurea and $Z$. dauma in south-east Asia has been reported (del Hoyo and Collar 2016) suggesting that these populations could be of hybrid origin.

The presence of birds with simple songs in Vietnam means that the simple singing horsfieldi of Indonesia no longer forms a geographic leapfrog pattern with the migratory simple singers of the far north, as was thought to be the case if the geographic range of complex singing $Z$. dauma extended from the Himalayas all the way to Vietnam (Fig. 1). However, other leapfrog patterns still do exist. Foremost, the insular range of $Z$. major is now even more strongly dissociated from the ranges of other complex singers if complex singing $Z$. dauma is restricted to the Himalayas. To the north of $Z$. major lies the range of the simple singing toratugumi in Japan, and simple singers also occur on Taiwan island to the south. The simple songs from the two birds from Taiwan island have narrow bandwidths and are similar to, and probably indistinguishable from the migratory toratugumi, but are distinct from geographically adjacent continental birds (e.g. Vietnam) which sing with increased bandwidth. A final leapfrog pattern involves the Sri Lankan endemic imbricata which is isolated from other simple singers in the far north and Southeast Asia, by the combined geographic ranges of the proximate neilgherriensis from the Western Ghats and the Himalayan dauma. Interestingly, imbricata groups closely with Indonesian horsfieldi in possessing strongly down-slurred whistled notes, a result that was not previously reported (e.g. by Clement and Hathway 2000). The presence of flat singing birds in Vietnam indicates another leapfrog pattern between these down-slurred singing taxa, or the possibility of an overwater dispersal event leading to the formation of these taxa. Assuming flat, down-slurred and complex singing taxa represent reciprocally monophyletic groupings (an assumption which cannot be verified without phylogenetic analysis of the complex), these geographic patterns suggest that long distance colonisations, or the generation of relict populations following a complex series of range expansions and contractions resulted in the current leapfrog patterns.

Should neilgherriensis be considered a distinct species? The complex song of this taxon clearly indicates it is vocally distinct from the simple singing taxa of $Z$. aurea with which it is currently considered conspecific by del Hoyo and Collar (2016). Whether neilgherriensis is specifically distinct from other complex singing taxa is more difficult to assess. Both neilgherriensis recordings grouped closely in PCA space, but these were somewhat differentiated along PC 1 from the sole recording available of $Z$. dauma from the western Himalayas. The latter had considerably greater strophe bandwidth. However, $Z$. major, for which I analyzed 10 recordings, occupied a large region of PCA space and possessed considerable variation in bandwidth across recordings. Some recordings of major possessed bandwidths as narrow as those of neilgherriensis (these lacked high pitched strophes above $5 \mathrm{kHz}$ ) while others had bandwidths greater than those of Himalayan dauma (these had strophes that extended up to $8 \mathrm{kHz}$ or more). $Z$. major also possessed considerable variation in strophe length across recordings which overlapped that of Himalayan dauma. The large variation observed within $Z$. major suggests that other complex singing taxa could have considerable variation in song across individuals, but more recordings are needed to verify this. If Himalayan dauma also possesses the same range of variation as $Z$. major, then neilgherriensis might not differ substantially from it and would probably best be considered a subspecies of $Z$. dauma when considering song characters alone. Given the low sample size of song recordings for neilgherriensis and dauma and the likely high variance in songs of dauma, I refrain from recommending that neilgherriensis be treated as specifically distinct from the Himalayan dauma at this time, though specific distinction may ultimately be the best option. Complex singers of the Zoothera mollisima complex have recently been shown to comprise at least two morphologically cryptic, sympatric species that separate elevationally and whose songs, though complex across all taxa involved, are nevertheless distinctive (Alström et al. 2016). These results for the $Z$. mollisima complex suggest that population differences in song composition amongst complex singers may contribute importantly to reproductive isolation, and the same may apply to the complex singers of the $Z$. dauma complex.

My data also suggest considerable variation in strophe shape and bandwidth amongst taxa which sing a simple, whistled song. On the basis of song differences alone, I suspect that the three groupings of simple singing taxa reported above could each represent distinct species level taxa. Additional species level taxa could be warranted if taking plumage divergence into account (i.e. imbricata and horsfieldi differ strongly in plumage, but less so in song). However, it would be premature to split these taxa now on the basis of so few vocal recordings.

\section{Conclusions}

These results suggest that the widespread taxon currently described as dauma sings simple songs in the east portion of its range and complex songs in the western 
Himalayas. Future work should aim to increase the sample size of recordings for dauma from both the east and west to determine if two taxa are involved, and if so, what their respective range limits are. My analyses also suggest that neilgherriensis sings complex songs highly distinct from $Z$. aurea with which it has been considered conspecific by del Hoyo and Collar (2016) and that it should either be regarded as a subspecies of $Z$. dauma or as its own distinct species. Additional species level taxa likely occur amongst the simple singing taxa, but a full taxonomic revision of the $Z$. dauma species complex will require a much larger sample size of vocal recordings, playback experiments between various taxa pairs, and detailed analyses of morphometrics, plumage, and genetics.

\section{Authors' contributions}

JTW obtained field recordings of the Nilgiri Thrush, performed analyses and wrote the manuscript. The author read and approved the final manuscript.

\section{Author details}

1 Department of Ecology and Evolutionary Biology, University of Toronto, Toronto, ON M1C 1A4, Canada. ${ }^{2}$ Department of Biological Sciences, University of Toronto Scarborough, Toronto, ON M1C 1A4, Canada. ${ }^{3}$ Department of Natural History, Royal Ontario Museum, Toronto, ON M5S 2C6, Canada.

\section{Acknowledgements}

Recordists who made their data publicly available or who personally contributed recordings helped make this study possible.

\section{Competing interests}

None.

Availability of data and materials

See Table 2.

\section{Consent for publication}

Several private recordings were provided to me as indicated in Table 2.
Ethics approval

Not applicable.

\section{Funding}

Funding was provided by an NSERC Postdoctoral fellowship, NSERC Discovery Grant (06538) and Accelerator Grant (492890) to JTW and by an NSF grant to

Trevor Price.

Received: 16 February 2018 Accepted: 20 August 2018

Published online: 23 August 2018

\section{References}

Alström P, Rasmussen PC, Zhao C, Xu J, Dalvi S, Cai T, Guan Y, Zhang R, Kalyakin MV, Lei FM, Olsson U. Integrative taxonomy of the plain-backed thrush (Zoothera mollissima) complex (Aves, Turdidae) reveals cryptic species, including a new species. Avian Res. 2016;7:1.

AvoCET. http://avocet.zoology.msu.edu. Accessed Oct to Dec 2017.

Clement P, Hathway R. Helm identification guides: thrushes. London: Christopher Helm; 2000.

del Hoyo J, Collar NJ. ICW and BirdLife international illustrated checklist of the birds of the world: passerines. Barcelona: Lynx Ediçions BirdLife International; 2016.

del Hoyo J, Elliott A, Sargatal J. Handbook of the birds of the world. Cuckooshrikes to thrushes, vol. 10. Barcelona: Lynx Ediçions and BirdLife International; 2005.

Macualay Library. http://macaulaylibrary.org. Accessed Oct 2017.

Rasmussen PC, Anderton JC. Birds of South Asia: the Ripley guide, vol. 2. BarceIona: Lynx Edicions; 2005.

Richmond CW. Descriptions of two new birds from Trong, Lower Siam. Proc Biol Soc Wash. 1902;15:157-8.

R Core Team. A language and environment for statistical computing. Vienna: R Foundation for Statistical Computing; 2017. http://www.R-project.org.

Sangster G, Hazevoet CJ, van den Berg AB, Roselaar CS. Dutch avifaunal list: species concepts, taxonomic instability, and taxonomic changes in 1998. Dutch Bird. 1998:20:22-32.

Thayer JE, Bangs O. Some Chinese vertebrates (Aves). Mem Mus Comp Zool. 1912:40:137-200.

Xeno-canto. http://www.xeno-canto.org. Accessed Oct to Dec 2017.
Ready to submit your research? Choose BMC and benefit from:

- fast, convenient online submission

- thorough peer review by experienced researchers in your field

- rapid publication on acceptance

- support for research data, including large and complex data types

- gold Open Access which fosters wider collaboration and increased citations

- maximum visibility for your research: over 100M website views per year

At BMC, research is always in progress.

Learn more biomedcentral.com/submissions 